\title{
Regimen Used to Treat Gestational Trophoblastic Tumor
}

National Cancer Institute

\section{Source}

National Cancer Institute. Regimen Used to Treat Gestational Trophoblastic Tumor. NCI

Thesaurus. Code C67509.

Any regimen that can be used for the treatment of gestational trophoblastic tumor. 